\title{
Embedding Cobalt Into ZIF-67 to Obtain Cobalt-Nanoporous Carbon Composites as Electrode Materials for Lithium ion Battery
}

\author{
Guoxu Zheng ${ }^{1,2 *}$, Jinghua Yin ${ }^{1}$, Ziqiang Guo ${ }^{3}$, Shiyi Tian ${ }^{4}$, and Xu Yang ${ }^{1}$ \\ ${ }^{1}$ Harbin University of Science and Technology, Harbin 150080, P. R. China \\ ${ }^{2}$ Hegang Coal and Graphene Testing Laboratory of Harbin Customs District Technical Center, Hegang 154100, P. R. China \\ ${ }^{3}$ School of Architecture, Chang'an University, Xi'an 710000, P. R. China \\ ${ }^{4}$ Zhejiang Post and Telecommunication College, School of Electronic and Communication Engineering, Shaoxing 312366 , \\ P. R. China
}

\begin{abstract}
Lithium ion batteries (LIBs) is a kind of rechargeable secondary battery, developed from lithium battery, lithium ions move between the positive and negative electrodes to realize the charging and discharging of external circuits. Zeolitic imidazolate frameworks (ZIFs) are porous crystalline materials in which organic imidazole esters are cross-linked to transition metals to form a framework structure. In this article, ZIF-67 is used as a sacrificial template to prepare nano porous carbon (NPC) coated cobalt nanoparticles. The final product Co/NPC composites with complete structure, regular morphology and uniform size were obtained by this method. The conductive network of cobalt and nitrogen doped carbon can shorten the lithium ion transport path and present high conductivity. In addition, amorphous carbon has more pores that can be fully in contact with the electrolyte during charging and discharging. At the same time, it also reduces the volume expansion during the cycle and slows down the rate of capacity attenuation caused by structure collapse. Co/NPC composites first discharge specific capacity up to $3115 \mathrm{~mA} \mathrm{~h} / \mathrm{g}$, under the current density of $200 \mathrm{~mA} / \mathrm{g}$, circular 200 reversible capacity as high as $751.1 \mathrm{~mA} \mathrm{~h} / \mathrm{g}$, and the excellent rate and resistance performance. The experimental results show that the Co/NPC composite material improves the electrical conductivity and electrochemical properties of the electrode. The cobalt based ZIF67 as the precursor has opened the way for the design of highly performance electrodes for energy storage and electrochemical catalysis.
\end{abstract}

Keywords : LIBs, ZIF-67, Co/NPC, Electrochemical Performance, Energy Storage

Received : 22 September 2020, Accepted : 31 May 2021

\section{Introduction}

With the rapid development of science and technology, human society's demand for energy is constantly increasing. However, low utilization rate of fossil energy and excessive exploitation of fossil energy lead to a series of environmental problems such as energy exhaustion, global warming and air pollution. Therefore, we need an efficient and clean new energy to solve the problems caused by the use of fossil fuels, and also put forward higher require-

*E-mail address: tsywrqwer@163.com

DOI: https://doi.org/10.33961/jecst.2020.01473

This is an open-access article distributed under the terms of the Creative Commons Attribution Non-Commercial License (http://creativecommons.org/licenses/by-nc/4.0)
which permits unrestricted non-commercial use, distribution, and reproduction in any which permits unrestricted non-commercial use, distri
medium, provided the original work is properly cited. ments for energy conversion and storage technology. LIBs have the advantages of environmental protection, high energy density, long cycle life, no memory effect and so on. It has become the research hotspot of new energy storage devices. When $\mathrm{Co}_{3} \mathrm{O}_{4}$ is used as electrode material for LIBs, the discharge capacity obtained in practical application is far lower than its theoretical value of $892 \mathrm{~mA} \mathrm{~h} / \mathrm{g}$. Moreover, the conductivity of $\mathrm{Co}_{3} \mathrm{O}_{4}$ material is low and the cycling stability is not satisfactory [1-4]. For this reason, researchers have used many methods to improve the conductivity of $\mathrm{Co}_{3} \mathrm{O}_{4}$, among which NPC materials with high surface area, adjustable aperture and ideal structure have entered the field of vision of the majority of researchers. The pore size distribution and surface area of nano-porous carbon play an important role in electrochemical performance. Vari- 
ous methods have been explored to prepare porous carbon and control its pore structure, including physical or chemical activation [5-6], carbide derived carbon (CDC) [7-8] and template carbonization [9-10], to improve specific capacity and cyclic stability. Metal-organic frameworks (MOFs) is a kind of coordination polymer that has been widely concerned in recent years. It is a new kind of crystalline material formed by the coordination between metal ions and organic ligands, and it has a periodic topological structure. Therefore, it has many advantages, such as large specific surface area, diverse structural functions, porosity and adjustable pore size [11]. With MOFs as the precursor, porous metal oxides and porous carbon materials with controllable structure can be obtained. As electrode materials, the electrochemical performance of the battery can be significantly improved. The derivatives of MOFs materials generally include metal oxides, metal hydroxides and carbon, etc. Through carbonizing MOFs materials, carbon and transition metal or transition metal oxide composite materials can be obtained. In fact, cobalt particles play an important role in improving electrode performance. In addition, cobalt can act as a catalyst to induce graphitization of carbon, so it is easy to make graphite layers to obtain NPC with high $\mathrm{SP}^{2}$-bonded carbon content, which have excellent intrinsic conductivity [12-13]. In this paper, cobalt nanoparticles were embedded into ZIF-67 by a simple method. The addition of cobalt can not only increase the active substance, but also cause the graphitization of carbon, which is expected to improve the electrochemical performance significantly.

\section{Experimental}

\subsection{Preparation of ZIF-67}

In the first step, $0.717 \mathrm{~g}$ of $\mathrm{Co}\left(\mathrm{NO}_{3}\right)_{2} \cdot 6 \mathrm{H}_{2} \mathrm{O}$ was dissolved in $50 \mathrm{ml}$ of deionized water and labeled as solution A, and 3.244g of 2-methylimidazole was dissolved in $50 \mathrm{ml}$ of deionized water and labeled as solution B. Step 2: dissolve $4 \mathrm{~g}$ of trimethylamine in B to obtain solution C. Step 3: pour solution $C$ into solution A, stir for 30 minutes, and mark as solution D. The fourth step is to wash and dry the solution D and collect the product, namely, ZIF-67.

\subsection{Preparation of Co-MOF and Co/NPC}

The first step was to dissolve $0.6 \mathrm{~g}$ of $\mathrm{Co}\left(\mathrm{NO}_{3}\right)_{2} \cdot 6 \mathrm{H}_{2} \mathrm{O}$

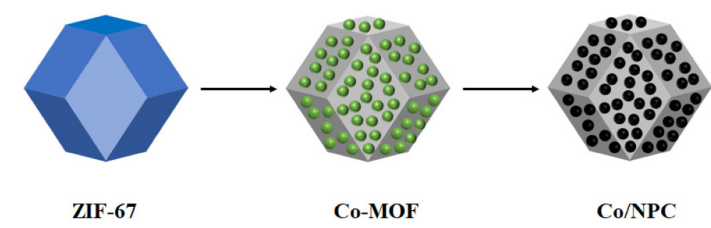

Fig. 1. Schematic diagram of Co/NPC composite material synthesis

and $0.5 \mathrm{~g}$ of ZIF- 67 in $10 \mathrm{~mL}$ of dimethyl sulfoxide one by one and stir them for $2 \mathrm{~h}$. The second step is washing and drying, and collecting the product, namely Co-MOF. The third step is to calcine the obtained Co-MOF in the argon gas flow, 650 ? was kept for $5 \mathrm{~h}$, then cooled to room temperature, the products were collected and $\mathrm{Co} / \mathrm{NPC}$ was obtained. As shown in Fig. 1.

\subsection{Material characterization}

The material characterization tests were carried out by X-ray diffraction (XRD), scanning electron microscope (SEM) and transmission electron microscope (TEM).

\subsection{Electrochemical measurement}

Prepare the electrode sheet. The prepared electrode material, Super-P carbon black (conductive additive) and binder (PVDF) are uniformly stirred with $\mathrm{N}$-methylpyrrolidone (solvent) in a ratio of $8: 1: 1$ to make a suspension. Secondly, the suspension is evenly dispersed on a round copper sheet, and a button battery (CR2302) is assembled in a glove box filled with argon gas. The constant current chargingdischarge test was completed by Wuhan Landian Battery Test System (CT2001A), including cyclic performance test and rate performance test. The voltage ranges from $0.01-3.00 \mathrm{~V}$. cyclic voltammetry (CV) and electrochemical impedance spectroscopy (EIS) were performed at Shanghai Chenhua Electrochemical Workstation, the reaction mechanism and interfacial resistance of electrode materials were analyzed. CV condition: voltage range is $0.01-3.00 \mathrm{~V}$, scanning speed: $0.01 \mathrm{mV} / \mathrm{s}$; EIS conditions: the frequency range is $0.01 \mathrm{HZ}-10^{6} \mathrm{~Hz}$, and the disturbance voltage is $10 \mathrm{mV}$.

\section{Results and Discussion}

Fig. 2 shows the XRD patterns of ZIF-67 and Co/ 

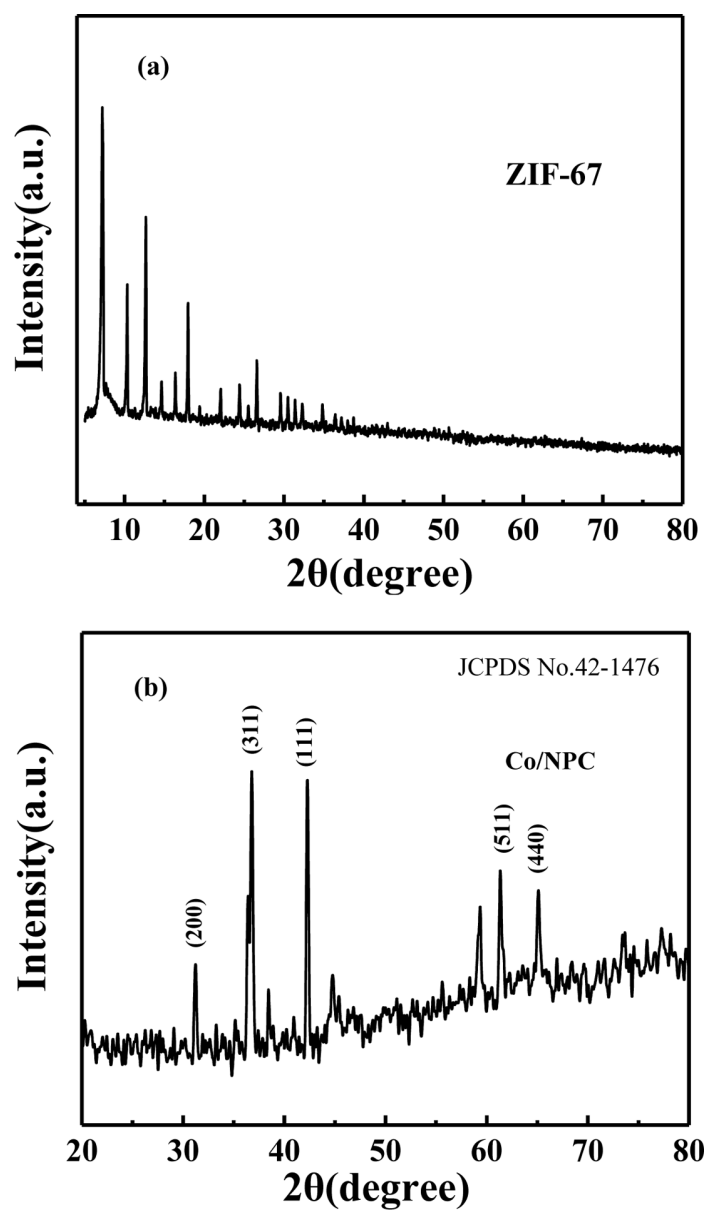

Fig. 2. XRD patterns of (a) ZIF-67 and (b) Co/NPC

NPC. Comparing the pattern with the XRD pattern of ZIF-67 in the literature [14], it is found that the position and intensity of the diffraction peaks of the prepared sample are basically the same as those of ZIF67. The characteristic peaks of ZIF-67 are in one-toone correspondence, so the preparation of ZIF-67 is successful. Compared with ZIF-67, the characteristic peak of cobalt in $\mathrm{Co} / \mathrm{NPC}$ became sharp, and the width of half peak decreased accordingly, indicating that the size and crystallinity of Co particles increased during the preparation of $\mathrm{Co} / \mathrm{NPC}$. The diffraction peaks of $\mathrm{Co} / \mathrm{NPC}$ at $30.9^{\circ}, 37.7^{\circ}, 59.2^{\circ}$ and $65.1^{\circ}$ were (200), (311), (511) and (440) crystal faces of cubic $\mathrm{Co}_{3} \mathrm{O}_{4}$ phase (JCPDS No.42-1476) [15]. The diffraction peak appears at $44.2^{\circ}$, corresponding to the (111) crystal surface of hexagonal cobalt. This

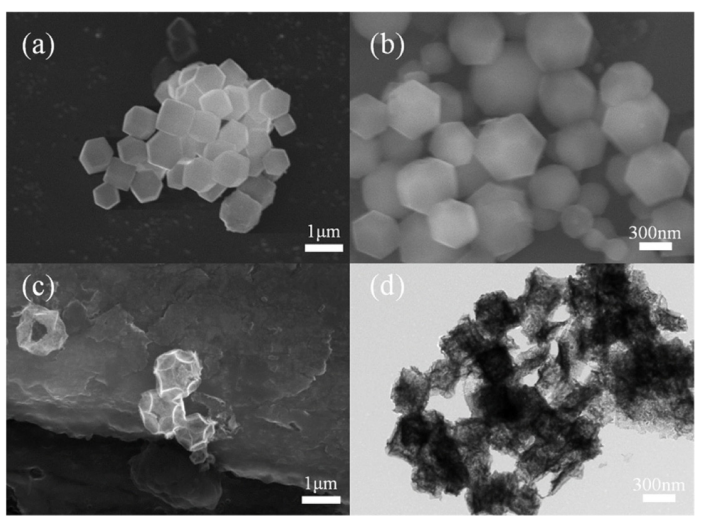

Fig. 3. SEM images of (a) ZIF-67, (b) Co-MOF, (c) Co/ NPC, TEM images of (d) Co/NPC

indicates that $\mathrm{Co} / \mathrm{NPC}$ was successfully synthesized.

As shown in Fig. 3(a), the synthesized ZIF-67 has a compact structure and uniform size, and presents a rhombic dodecahedron structure with a very smooth surface. Fig. 3(b) is the SEM image of Co-MOF, which maintains the structure and morphology of the precursor dodecahedron. Fig. 3(c) shows the Co/NPC composite material. It can be seen that the average diameter of the dodecahedral structure of the $\mathrm{Co} /$ NPC composite material is between $300-500 \mathrm{~nm}$, the general morphology of Co-MOF was maintained, but the overall shrinkage occurred along the direction of the surface center. This is mainly because during the carbonization process, the coordination bond between cobalt metal and organic connector breaks, the dodecahedron shrinks towards the center of the crystal, the structure edges are more prominent, and different degrees of folds appear on each surface, resulting in macroscopic deformation. In Fig. 3(d), it is clearly observed that the cobalt particles are tightly attached to the surface or embedded within the crystal, indicating that the embedded cobalt particles successfully adhere to the ZIF-67 without damaging the structure.

Using Co/NPC composite as the working electrode and lithium as the reference electrode, the button battery was assembled to test its electrochemical performance. Fig. 4 shows its $\mathrm{CV}$ curve at $0.01 \mathrm{mV} / \mathrm{s}$ scanning speed within the range of 0.01-3.00 V. The first $\mathrm{CV}$ curve of $\mathrm{Co} / \mathrm{NPC}$ composites is significantly different from the subsequent curve, which can be attributed to the formation of amorphous $\mathrm{Li}_{2} \mathrm{O}$ and 


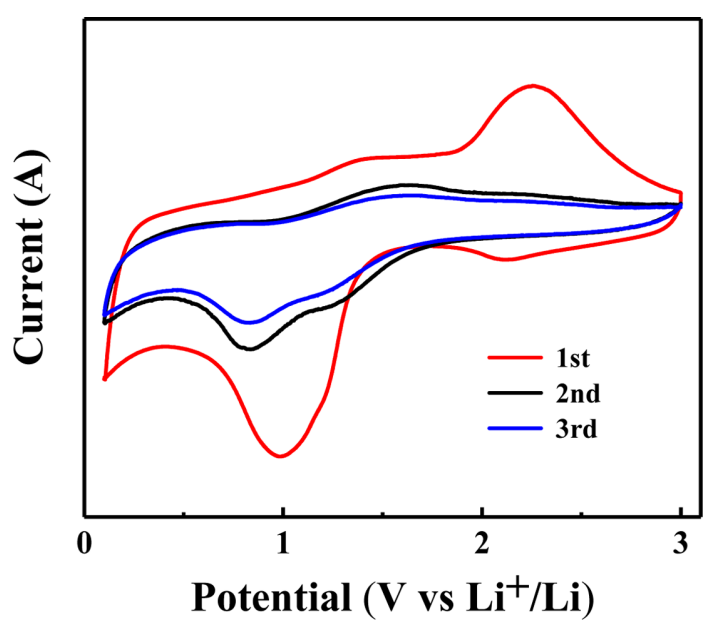

Fig. 4. Cyclic voltammetry curve of $\mathrm{Co} / \mathrm{NPC}$

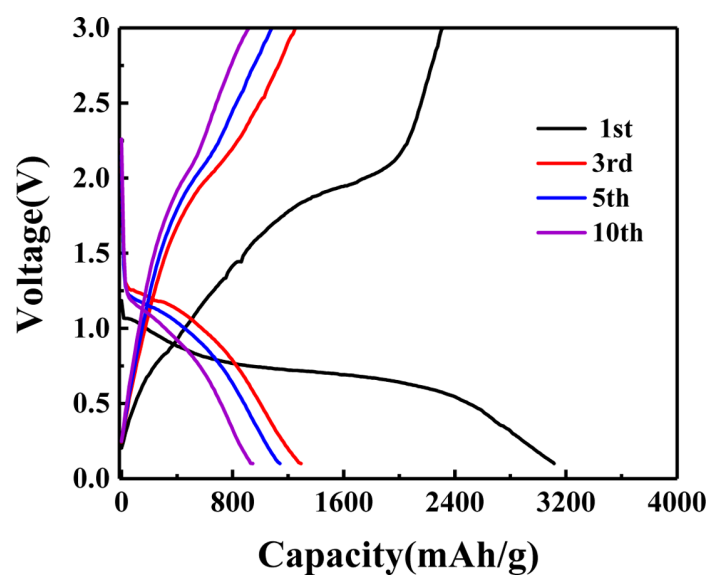

Fig. 5. Charging and discharging curves of $\mathrm{Co} / \mathrm{NPC}$

passivated solid electrolyte interface (SEI) membranes $[16,17]$. In the first cathode scan, two reduction peaks appeared at about $1 \mathrm{~V}$ and $2.1 \mathrm{~V}$, which was due to the reduction of $\mathrm{Co}^{2+}$ and $\mathrm{Co}^{3+}$ into metal Co. The two oxidation peaks around $1.5 \mathrm{~V}$ and $2.25 \mathrm{~V}$ in the anodic scan were due to the oxidation process of $\mathrm{Co}_{0} \mathrm{Co}^{3+}$ and $\mathrm{Co}^{2+}[18,19]$.

In the subsequent cycle, the oxidation/reduction peak gradually shifted, the reduction peak stabilized at about $0.8 \mathrm{~V}$, and the oxidation peak stabilized at about $1.5 \mathrm{~V}$ respectively. It is worth noting that the second CV curve and the third CV curve basically coincide, indicating that the lithium deactivation and

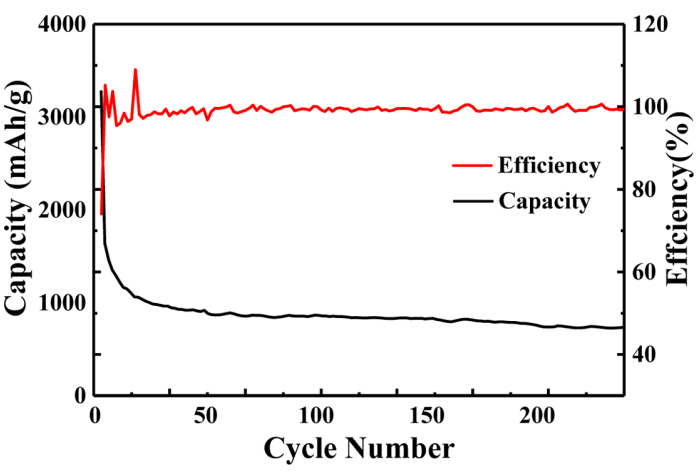

Fig. 6. Cyclic performance curves of $\mathrm{Co} / \mathrm{NPC}$.

lithium intercalation reactions of $\mathrm{Co} / \mathrm{NPC}$ composite materials have good invertibility.

Fig. 5 shows the constant current discharge/charge cycle curves of $\mathrm{Co} / \mathrm{NPC}$ composites at the current density of $200 \mathrm{~mA} / \mathrm{g}$ in the range of $0.01-3.00 \mathrm{~V}$, in the first, third, fifth and tenth turns. The initial discharge specific capacity is $3115 \mathrm{~mA} \mathrm{~h} / \mathrm{g}$, the initial charge specific capacity is $2307.5 \mathrm{~mA} \mathrm{~h} / \mathrm{g}$, and the Coulomb efficiency is $74 \%$. The charge/discharge curve at different voltages can correspond to the $\mathrm{CV}$ curve. The initial capacity loss is mainly due to various irreversible processes, such as interface lithium storage, solid electrolyte interface (SEI layer) and the formation of organic conductive polymer, as well as electrolyte decomposition. This phenomenon is very common in most anode materials. Starting from the third turn, the discharge and charging platforms appear around $0.75 \mathrm{~V}$ and $1-1.5 \mathrm{~V}$ correspond to the Redox peak of CV curve.

To further understand the cycling performance of the Co/NPC composite material, the battery was cycled 200 times at $200 \mathrm{~mA} / \mathrm{g}$. It is obvious from Fig. 6 that $\mathrm{Co} / \mathrm{NPC}$ composites have high reversible capacity and excellent cycling performance. The initial discharge and specific charging capacity of the $\mathrm{Co} / \mathrm{NPC}$ composite electrode reached $3115 \mathrm{~mA} \mathrm{~h} / \mathrm{g}$ and $2307.5 \mathrm{~mA} \mathrm{~h} / \mathrm{g}$ respectively, and after 200 cycles, the specific discharge capacity could be maintained at $751.1 \mathrm{~mA} \mathrm{~h} / \mathrm{g}$. The density and size of $\mathrm{Co} / \mathrm{NPC}$ composites can adapt to the volume changes caused by the lithium/lithium deferral process, without the agglomeration of nanostructures. The amorphous carbon produced by carbonization of ZIF-67 material has many defects. It not only reacts with lithium to form compound $\mathrm{Li}_{3} \mathrm{C}$, but also provides more 
capacity. In addition, the electrolyte decomposes and forms the SEI film during the cycling process. The process of lithium-ion adsorption and desorption on SEI films can also increase lithium storage capacity [21], thus maintaining a high specific capacity and showing excellent cycling performance. As shown in the Fig. 7. At the current density of $200 \mathrm{~mA} / \mathrm{g}$, the capacity of Co/NPC composite electrode was $751.1 \mathrm{~mA} \mathrm{~h} / \mathrm{g}$. With the increase of current density, the capacity decreases gradually. The capacities of $400 \mathrm{~mA} / \mathrm{g}, 800 \mathrm{~mA} / \mathrm{g}, 1200 \mathrm{~mA} / \mathrm{g}, 1600 \mathrm{~mA} / \mathrm{g}$ and $2000 \mathrm{~mA} / \mathrm{g}$ are respectively $696 \mathrm{~mA} \mathrm{~h} / \mathrm{g}, 493 \mathrm{~mA} \mathrm{~h} / \mathrm{g}$, $348 \mathrm{~mA} \mathrm{~h} / \mathrm{g}, 261 \mathrm{~mA} \mathrm{~h} / \mathrm{g}$ and $258 \mathrm{~mA} \mathrm{~h} / \mathrm{g}$. This excellent multiplier performance is better than that of similar $\mathrm{Co}_{3} \mathrm{O}_{4}$ materials reported in many literatures [22-24]. As shown in Table 1. More importantly, after the rate performance test is completed, the battery discharge capacity can be fully recovered $(751.1 \mathrm{~mA}$ $\mathrm{h} / \mathrm{g}$ ) when the current density becomes $200 \mathrm{~mA} / \mathrm{g}$.

The impedance spectrogram is composed of two parts. In the high frequency and low frequency regions, there is a semicircle and a straight line. For

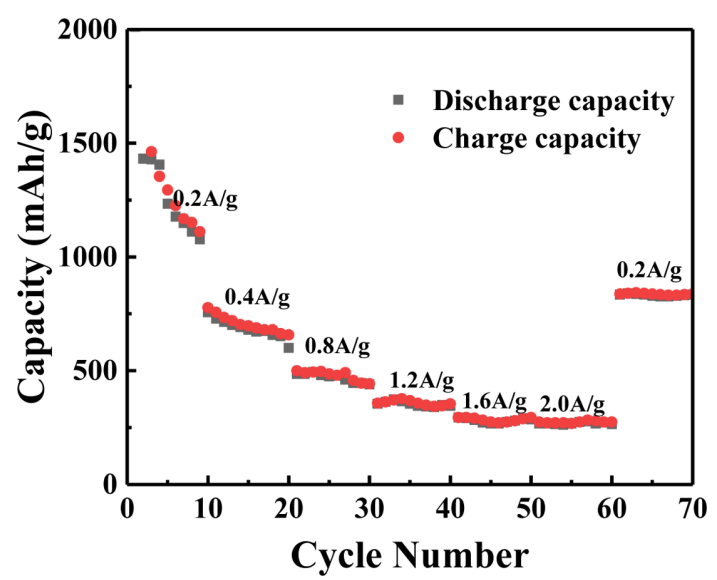

Fig. 7. rate performance curve of $\mathrm{Co} / \mathrm{NPC}$ transition metal oxide anode materials, the former refers to the charge transfer resistance and the resistance of the SEI film. The latter refers to the Warburg impedance caused by the transfer of matter [25]. As shown in Fig. 8, compared to the radius of the $\mathrm{Co}_{3} \mathrm{O}_{4}$ curve, the semicircle diameter of the $\mathrm{Co} / \mathrm{NPC}$ highfrequency region is significantly smaller, indicating

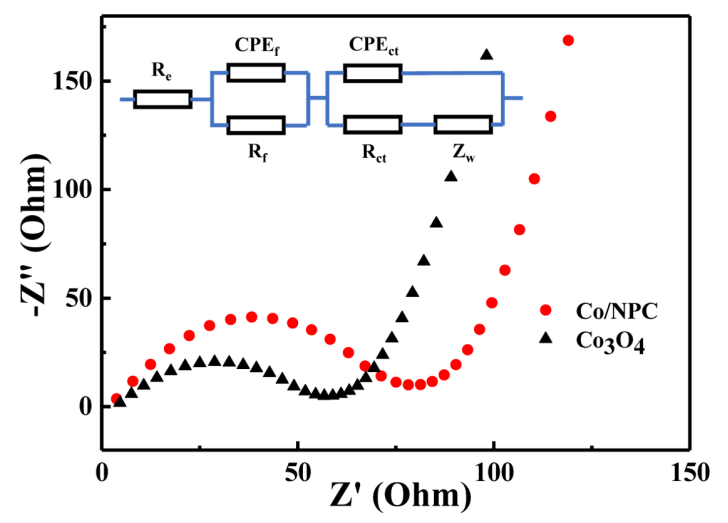

Fig. 8. AC impedance curve of $\mathrm{Co} / \mathrm{NPC}$ and $\mathrm{Co}_{3} \mathrm{O}_{4}$

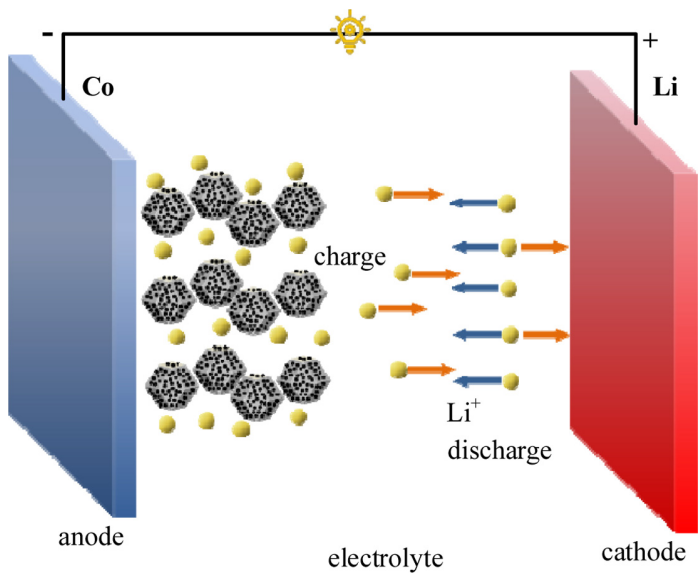

Fig. 9. Lithium inserting mechanism

Table 1. Comparison of performance

\begin{tabular}{cccc}
\hline \hline Typical examples & Current density & Capacity & Ref. \\
\hline $\mathrm{Co} / \mathrm{NPC}$ & $200 \mathrm{~mA} / \mathrm{g}$ & $751.1 \mathrm{~mA} \mathrm{~h} / \mathrm{g}$ after 200 cycles & This work \\
$\mathrm{Co} / \mathrm{NPC}$ & $1000 \mathrm{~mA} / \mathrm{g}$ & $425 \mathrm{~mA} \mathrm{~h} / \mathrm{g}$ after 50 cycles & This work \\
$\mathrm{Co}_{3} \mathrm{O}_{4}-\mathrm{C}$ & $200 \mathrm{~mA} / \mathrm{g}$ & $712 \mathrm{~mA} \mathrm{~h} / \mathrm{g}$ after 30 cycles & {$[22]$} \\
$\mathrm{Co}_{3} \mathrm{O}_{4}$ & $100 \mathrm{~mA} / \mathrm{g}$ & $743 \mathrm{~mA} \mathrm{~h} / \mathrm{g}$ after 50 cycles & {$[23]$} \\
$\mathrm{Co}_{3} \mathrm{O}_{4} @ \mathrm{MnO}_{2}$ & $1000 \mathrm{~mA} / \mathrm{g}$ & $387 \mathrm{~mA} \mathrm{~h} / \mathrm{g}$ after 45 cycles & {$[24]$} \\
\hline
\end{tabular}


that its impedance value is lower and the charge transfer efficiency is higher. This is mainly because metallic cobalt, as an excellent electronic conductor, makes up for the shortcomings of poor conductivity of $\mathrm{Co}_{3} \mathrm{O}_{4}$. At the same time, the addition of carbon materials makes it easier for the charge to be transferred between the electrolyte and the active material.

The intercalation mechanism model of lithium in the $\mathrm{Co} / \mathrm{NPC}$ array material is shown in Fig. 9. The lithium storage mechanism of $\mathrm{Co}_{3} \mathrm{O}_{4}$ material is a conversion mechanism, and the reaction equation is as follows:

$$
\begin{aligned}
& \mathrm{Co}_{3} \mathrm{O}_{4}+2 \mathrm{Li}^{+}+2 \mathrm{e}^{-} \rightarrow 3 \mathrm{CoO}+\mathrm{Li}_{2} \mathrm{O} \\
& \mathrm{CoO}+2 \mathrm{Li}^{+}+2 \mathrm{e}^{-} \rightarrow \mathrm{Co}+\mathrm{Li}_{2} \mathrm{O} \\
& \mathrm{Co}+\mathrm{Li}_{2} \mathrm{O} \rightarrow \mathrm{CoO}+2 \mathrm{Li}^{+}+2 \mathrm{e}^{-} \\
& 3 \mathrm{CoO}+\mathrm{Li}_{2} \mathrm{O} \rightarrow \mathrm{Co}_{3} \mathrm{O}_{4}+2 \mathrm{Li}^{+}+2 \mathrm{e}^{-}
\end{aligned}
$$

During the discharge process, $\mathrm{Co}_{3} \mathrm{O}_{4}$ reacts with lithium ions to be reduced to metallic $\mathrm{Co}$, and amorphous lithium oxide $\left(\mathrm{Li}_{2} \mathrm{O}\right)$ is produced; during the charging process, metallic Co reacts with lithium oxide $\left(\mathrm{Li}_{2} \mathrm{O}\right)$ to generate $\mathrm{Co}_{3} \mathrm{O}_{4}$ and lithium ions. During the reaction, there is a reversible redox of $\mathrm{Co}_{3} \mathrm{O}_{4}$, as well as the formation and decomposition of $\mathrm{Li}_{2} \mathrm{O}$. The presence of metallic cobalt effectively increases the conductivity of $\mathrm{Co}_{3} \mathrm{O}_{4}$ and can improve the electron transfer rate of the material; the good synergistic effect between $\mathrm{Co}_{3} \mathrm{O}_{4}$ particles and amorphous carbon can not only buffer the volume change in the repeated lithium removal/lithium insertion process, but also Conducive to the rapid transfer of electrons and lithium ions.

\section{Conclusions}

In this paper, ZIF-67 was successfully synthesized by the one-step method, and the Co/NPC composite was further synthesized using ZIF-67 as the template. The microscopic morphology and crystal structure of the composite material were tested by XRD, SEM and TEM. The prepared Co/NPC composite material has a dodecahedral structure and uniform size. The first discharge specific capacity of the Co/NPC composite material is as high as $3115 \mathrm{~mA} \mathrm{~h} / \mathrm{g}$, and at a current density of $200 \mathrm{~mA} / \mathrm{g}$, the reversible capacity is as high as $751.1 \mathrm{~mA} \mathrm{~h} / \mathrm{g}$ after 200 cycles, and it has excellent rate and impedance performance. Co/NPC composite material, as a lithium battery anode material, exhibits excellent battery performance, mainly due to the conductive network formed by metal cobalt and carbon, which effectively shortens the lithium ion transmission path and improves the conductivity of the composite material; at the same time, it also reduces The volume expansion produced during the cycle delays the capacity attenuation caused by structural collapse. The existence of pores can also serve as a buffer space for the volume expansion of the electrode material during the lithium ion insertion/extraction process, alleviating the internal stress of the electrode material, and increasing the electrode/electrolyte contact area, making the electrochemical reaction more easily and fully.

\section{Acknowledgments}

The authors acknowledge financial support from Natural Science Foundation of China (51502063), China Postdoctoral Science Foundation (2016T90306 and 2015M570301), Natural Science Foundation (E2015064) and Postdoctoral Science Foundation (LBH-TZ0615) of Heilongjiang Province of China, Natural Science Foundation of Heilongjiang Province of China (Geant No.F2017017), and Science Funds for Young Innovative Talents of HUST (201505). National undergraduate innovation and entrepreneurship training program (project No.201910214016 and No.201910214005). Research initiation fund of Hainan University (No. KYQD(ZR)20062). This work is supported by Hei Long Jiang Postdoctoral Foundation (LBH-Z20082).

\section{References}

[1] G. Huang, F. Zhang, X. Du, ACS Nano, 2015, 9(2), 1592-1599.

[2] W. Hao, S. Chen, Y. Cai, J. Mater. Chem. A, 2014, 2(34), 13801-13804.

[3] X. Wang, X.L. Wu, Y.G. Guo, Adv. Funct. Mater, 2010, 20(10), 1680-1686.

[4] N. Venugopal, D.J. Lee, Y.J. Lee, J. Mater. Chem. A, 2013, 1(42), 13164-13170

[5] H. Gong, Z. Chen, Y. Fan, Renew. Energ., 2015, 83, 144-150.

[6] V. Subramanian, C. Luo, A.M. Stephan, J. Phys. Chem. C, 2007, 111(20), 7527-7531.

[7] M. Arulepp, J. Leis, M. Latt, J. Power Sources, 2006, 
162(2), 1460-1466.

[8] Y. Gogotsi, A. Nikitin, H. Ye, Nat. Mater., 2003, 2(9), 591.

[9] H. Juan, Carbon, 2010, 48(12), 3599-3606.

[10] W. Chaikittisilp, M. Hu, H. Wang, Chem. Commun., 2012, 48(58), 7259-7261.

[11] S.Y. Tian, G.X. Zheng, Q. Liu, M.Y. Ren, J.H. Yin, Int J. Electrochem. Sci., 2019, 14, 9459-9467.

[12] N.L. Torad, R.R. Salunkhe, Y.Q. Li, Chem-Eur. J., 2014, 20(26), 7895-7900

[13] L. Zhi, Y.S. Hu, B.E. Hamaoui, Adv. Mater, 2008, 20(9), 1727-1731.

[14] Y. Chen, X. Ji, J. Alloy. Compd., 2019, 777, 688-692.

[15] F. Chen, Y.F. Yuan, L.W. Ye, Mater. Lett., 2019, 237, 213-215.

[16] B. Guo, C. Li, Z.Y. Yuan. J. Phys. Chem. C, 2010, 114, 12805-12817.

[17] D. Gu, W. Li, F. Wang, Angew. Chem. Int. Edit., 2015,
$54,7060-7064$.

[18] Z.S. Wu, W. Ren, L. Wen, ACS Nano, 2010, 4, 31873194 .

[19] L. Wang, Y. Zheng, X. Wang, ACS Appl. Mater. Inter, 2014, 6, 7117-7125.

[20] L. Peng, Y. Feng, Y. Bai, J. Mater. Chem. A, 2015, 3, 8825-8831.

[21] X. Leng, Y. Shao, L. Wu, J. Mater. Chem. A, 2016, 4(26), 10304-10313.

[22] J. Chen, X.H. Xia, J.P. Tu, J. Mater. Chem., 2012, 22 (30), 15056-15061.

[23] C.C. Li, Q.H. Li, L.B. Chen, J. Mater. Chem., 2011, 21 (32), 11867-11872.

[24] D. Kong, J. Luo, Y. Wang, Adv. Funct. Mater, 2014, 24 (24), 3815-3826.

[25] X. Leng, S. Wei, Z. Jiang, Sci. Rep-UK., 2015, 5, 16629. 